\title{
Fungsi Ekstrakurikuler Karawitan di Sekolah Dasar Negeri Sendangguwo 01 Semarang
}

\author{
*Cahya Prabowo ${ }^{1}$, Prasena Arisyanto², Aries Tika Damayani ${ }^{3}$ \\ ${ }^{123}$ Pendidikan Guru Sekolah Dasar, Fakultas Keguruan dan Ilmu Pendidikan, Universitas Halmahera, Indonesia
}

\author{
A R T I C L E I N F O \\ Article history: \\ Received 15 August 2019 \\ Received in revised form \\ 20 September 2019 \\ Accepted 10 October 2019 \\ Available online 30 \\ November 2019 \\ Kata Kunci: \\ fungsi ekstrakurikuler, \\ karawitan \\ Keywords: \\ extracurricular function, \\ karawitan
}

\begin{abstract}
A B S T R A K
Karawitan merupakan suatu keahlian, ketrampilan, kemampuan, atau seni memainkan, menggarap, atau mengolah suatu gendhing (lagu tradisional dalam seni karawitan Jawa yang dimainkan menggunakan alat musik gamelan) sehingga menjadi bagian-bagian kecil yang bersifat renik, rinci, dan halus. Kegiatan ekstrakurikuler karawitan ini bertujuan untuk mengenalkan dan memberikan gambaran awal kepada siswa mengenai seni karawitan. Penelitian ini bertujuan untuk Mengetahui fungsi ekstrakurikuler karawitan bagi Sekolah dan siswa. Jenis penelitian ini adalah kualitatif deskriptif. Pengumpulan data dalam penelitian ini dilakukan dengan metode wawancara, observasi, dan angket. Subjek penelitian adalah siswa dan pelatih karawitan di SD. Dari hasil penelitian, Pelaksanaan kegiatan ekstrakurikuler karawitan di SD dilaksanakan di luar jam kegiatan belajar mengajar. Pembelajaran ekstrakurikuler karawitan di bagi menjadi 3 kegiatan yaitu kegiatan
\end{abstract} pendahuluan, kegiatan inti, dan kegiatan penutup. Fungsi ekstrakurikuler karawitan bagi sekolah yaitu menanamkan cinta budaya sejak dini dan dapat memajukan SD atas prestasi karawitan. Sedangkan fungsi ekstrakurikuler karawitan bagi siswa yaitu pengembangan personal siswa melalui peluasan minat, pengembangan kemampuan dan rasa tanggung jawab. Berdasarkan penelitian ini saran yang disampaikan kepada Sekolah hendaknya mempertahankan dan meningkatkan kegiatan ekstrakurikuler karawitan agar ekstrakurikuler karawitan menjadi wadah bagi siswa untuk pengembangan diri siswa dan mempelajari kebudayaan lokal sehingga dapat melestarikan kebudayaan lokal.

\begin{abstract}
A B S T R A C T
This type of research is descriptive qualitative. Data collection in this study was conducted by interview, observation and questionnaire. The research subjects were students and musical trainers at SDN Sendangguwo 01 Semarang. From the results of the study, the implementation of karawitan extracurricular activities at SDN Sendangguwo 01 Semarang was held outside of teaching and learning hours. Karawitan extracurricular learning is divided into 3 activities namely preliminary activities, core activities, and election activities. Karawitan extracurricular function for schools is to instill cultural love from an early age and can advance Sendangguwo 01 Semarang Elementary School on musical performance. While musical extracurricular functions for students are the personal development of students through complementary interests, ability development and a sense of responsibility. Based on this research, the advice submitted to the School is the need to maintain and improve musical extracurricular activities so that extracurricular musicians become a place for students to develop themselves and develop local agriculture so that they can be used to preserve local sports.
\end{abstract}

\section{Pendahuluan}

Salah satu upaya pemerintahan dalam memperkenalkan kebudayaan Indonesia kepada generasi muda adalah melalui jalur pendidikan. Pendidikan adalah kehidupan, untuk itu kegiatan harus dapat membekali peserta didik dengan kecakapan hidup (life skill atau life competency) yang sesuai dengan lingkungan kehidupan dan kebutuhan peserta didik (Mulyasa, 2016). Undang-Undang Republik Indonesia

Copyright (C) Universitas Pendidikan Ganesha. All rights reserved. 
Nomor 20 Tahun 2003 tentang Sistem Pendidikan Nasional Pasal 1 menyebutkan bahwa pendidikan nasional adalah pendidikan yang berdasarkan Pancasila dan Undang-Undang Dasar Negara Republik Indonesia Tahun 1945 yang berakar pada nilai-nilai agama, kebudayaan nasional Indonesia dan tanggap terhadap tuntutan perubahan zaman. Undang-Undang Sistem Pendidikan Nasional Nomor 20 Tahun 2003 menyatakan bahwa Pendidikan Nasional bertujuan untuk mengembangkan potensi peserta didik agar menjadi manusia yang beriman dan bertakwa kepada Tuhan Yang Maha Esa, berakhlak mulia, sehat, berilmu, cakap, kreatif, mandiri dan menjadi warga negara yang demokratis serta bertanggung jawab. Peraturan Menteri Pendidikan dan Kebudayaan nomor 62 tahun 2014 tentang Kegiatan Ekstrakurikuler adalah kegiatan kurikuler yang dilakukan oleh peserta didik di luar jam belajar kegiatan intrakurikuler dan kegiatan kokurikuler, di bawah bimbingan dan pengawasan satuan pendidikan. (Undang-Undang Nomor 62 Tahun 2014). Menurut (Syakir et al., 2017) Pendidikan merupakan salah satu kegiatan yang berguna untuk mencerdaskan kehidupan bangsa, karena pendidikan mampu membentuk karakter suatu bangsa. Apabila pendidikan disuatu negara maju secara otomatis negara tersebut akan menjadi negara yang maju pula.

Ekstrakurikuler merupakan kegiatan pendidikan diluar jam pelajaran yang ditunjukkan untuk membantu perkembangan peserta didik atau tenaga kependidikan yang berkemampuan dan berkewenangan disekolah (Wiyani, 2013) dalam Jurnal Pendidikan Kewarganegaraan. (Hambali \& Yulianti, 2018) Kegiatan ekstrakurikuler merupakan proses menyempurnakan pendidikan pada tingkat kognitif menuju berkesinambungan ke aspek afektif dan psikomotorik sehingga dapat menjebatani masalah pendidikan sekolah dengan pendidikan di keluarga dan tantangan arus deras globalisasi bagi negera-negara berkembang, Indonesia. Secara umum, lembaga pendidikan swasta standar mutunya dari aspek pendidik berorientasi pada ijazah formal, sarana belajar berorientasi dan tradisi belajar berorientasi pada kemampuan menjawab soal UNBK. (Fitri et al., 2018) Kegiatan ekstrakurikuler menjadi salah satu program yang diselenggarakan sekolah dan merupakam media potensial untuk pembinaan karakter dan peningkatan mutu akademik peserta didik untuk membantu mengembangkan peserta didik sesuai dengan kebutuhan, potensi, bakat dan minat masing-masing. (Wiyani, 2013) ekstrakurikuler merupakan kegiatan pendidikan yang dilakukan di luar jam pelajaran tatap muka dengan tujuan memperluas pengetahuan, meningkatkan keterampilan, dan menginternalisasi nilai-nilai dan norma.

Karawitan merupakan suatu keahlian, ketrampilan, kemampuan, atau seni memainkan, menggarap, atau mengolah suatu gendhing (lagu tradisional dalam seni karawitan Jawa yang dimainkan menggunakan alat musik gamelan) sehingga menjadi bagian-bagian kecil yang bersifat renik, rinci, dan halus (Endraswara, n.d.). Karawitan mempunyai dua arti yaitu: arti umum dan arti khusus. Dalam arti umum, berarti musik Jawa tradisional, dalam arti khusus adalah seni suara vokal, yang dikemas dengan instrumentalia yang berlaras slendro dan pelog (Sidik, 2018). Secara khusus, istilah karawitan lebih mengacu pada pengertian seni suara yang mengemukakan garnelen laras slendro dan laras pelog. Melalui pendidikan seni, berbagai kemampuan dasar manusia seperti fisik, perseptual, pikir, emosional, kreativitas, sosial, dan estetika dapat dikembangkan. Berbagai kemampuan dasar yang dapat dioptimalkan akan menghasilkan tingkat kecerdasan, emosional, intelektual, kreatif, dan moral (Yeti (Arisyanto et al., 2018)).

Kelebihan dalam penelitian ini adalah agar siswa sekolah dasar dapat menanamkan dan mengembangkan karakter yang baik, tidak hanya dalam kegiatan proses pembelajaran akan tetapi juga melalui kegiatan ekstrakurikuler karawitan.

Berdasarkan hasil observasi dan wawancara pada guru (pelatih karawitan) di Sekolah Dasar Negeri Sendangguwo 01 Semarang, bahwa ekstrakurikuler karawitan juga diterapkan di Sekolah Dasar Negeri Sendangguwo 01 Semarang. Kegiatan ekstrakurikuler karawitan ini bertujuan untuk mengenalkan dan memberikan gambaran awal kepada siswa mengenai seni karawitan. Terlebih dahulu pelatih menjelaskan kepada siswa bahwa seni karawitan merupakan kesenian yang dibawakan secara berkelompok, suatu proses pembelajaran yang menerapkan kerjasama dalam sebuah tim, sehingga dalam memainkan alat musik gamelan siswa harus dapat saling bekerjasama.

Kegiatan ekstrakurikuler yang ada di Sekolah Dasar Negeri Sendangguwo 01 Semarang merupakan kegiatan ekstrakurikuler yang diwajibkan untuk siswa kelas III, IV, dan V. Kegiatan ekstrakurikuler karawitan ini diadakan pada hari selasa. Kegiatan ekstrakurikuler karawitan yang diadakan oleh pihak sekolah sangat membantu siswa dalam pengenalan budaya, pengembangan bakat minat, pengembangan ketrampilan siswa, pengembangan karakter siswa. Respon siswa dengan diadakan kegiatan ekstrakurikuler karawitan sangat baik sehingga memicu samangat guru (pelatih karawitan) untuk melatih siswa.

Berdasarkan hasil wawancara dengan guru (pelatih karawitan) di Sekolah Dasar Negeri Sendangguwo 01 Semarang, kegiatan ekstrakurikuler karawitan pernah menjuarai lomba karawitan, pada 
tahun 2018 mendapatkan juara II tingkat kota semarang dan pada tahun 2019 mendapatkan juara I tingkat kota semarang dalam acara gelar pendidikan karakter bidang pembinaan SD tahun 2019.

Dari uraian diatas, dapat disimpulkan bahwa pendidikan merupakan hak setiap warga negara dan bahkan hak setiap insan, tidak melihat latar belakang dari siapa dia dan dari mana asalnya, kaya atau miskin, namun yang menjadi permasalahannya adalah bagaimana fungsi ekstrakurikuler karawitan bagi siswa dan sekolah. Berdasarkan latar belakang masalah tersebut, maka penulis tertarik untuk melakukan penelitian dengan judul "Fungsi Ekstrakurikuler Karawitan Di Sekolah Dasar Negeri Sendangguwo 01 Semarang". Adapun tujuan penelitian yang dilakukan adalah sebagai berikut: (1) Mengetahui pelaksanaan ekstrakurikuler karawitan di Sekolah Dasar Negeri Sendangguwo 01 Semarang. (2) Mengetahui fungsi ekstrakurikuler karawitan bagi Sekolah Dasar Negeri Sendangguwo 01 Semarang. (3) Mengetahui fungsi ekstrakurikuler karawitan bagi pengembangan diri siswa di Sekolah Dasar Negeri Sendangguwo 01 Semarang.

\section{Metode}

Penelitian ini menggunakan metode kualitatif yang bertujuan untuk mendeskripsikan Fungsi Ekstrakurikuler Karawitan Sebagai Pengembangan Karakter Pada Siswa. Penelitian kualitatif merupakan suatu penelitian yang digunakan untuk mendekripsikan dan menganalisis fenomena, kejadian, aktifitas sosial, sikap, kepercayaan, persepsi, pemikiran, orang secara perseorangan maupun berkelompok (Sukmadinata, 2016). (Sugiyono, 2017a) mengemukakan bahwa metode penelitian kualitatif merupakan metode penelitian yang didasari oleh filsafat postpositivisme, yang digunakan untuk meneliti pada keadaan objek yang bersifat alamiah, dimana penelti bertindak sebagai pemegang kunci, teknik pengumpulan data dilakukan secara triangulasi, analisis data bersifat kualitatif dan hasil dari penelitian lebih terfokuskan kepada makna dari pada generalisasi.

Pendekatan yang akan dilakukan adalah deskriptif kualitatif yang dilakukan dengan menguraikan fakta-fakta atau data-data yang diperoleh dari sumber data. Data-data tersebut selanjutnya akan dideskripsikan dengan Fungsi Ekstrakurikuler Karawitan Di Sekolah Dasar Negeri Sendangguwo 01 Semarang.

Pemilihan lokasi penelitian perlu dirumuskan dengan jelas, terutama fokus penelitian, satuan yang dipilih hendaknya secara nyata dimana kegiatan-kegiatan tersebut efektif dilaksanakan. (Sukmadinata, 2016).

Lokasi penelitian adalah tempat dimana penelitian berlangsung. Penelitian ini akan dilaksanakan di Sekolah Dasar Negeri Sendangguwo 01 Semarang dengan fokus penelitian yaitu fungsi ekstrakurikuler karawitan di Sekolah Dasar Negeri Sendangguwo 01 Semarang, Karena di Sekolah Dasar Negeri Sendangguwo 01 Semarang tersebut seni karawitan merupakan hal yang menyenangkan, diminati oleh siswa, dan telah beberapa kali mendapatkan prestasi yang baik.

Subjek penelitian yang akan diteliti adalah kepala sekolah, pelatih karawitan, dan siswa di Sekolah Dasar Negeri Sendangguwo 01 Semarang ketika pelaksanaan ekstrakurikuler karawitan. Adapun yang diteliti yaitu fungsi ekstrakurikuler karawitan bagi sekolah dan siswa di Sekolah Dasar Negeri Sendangguwo 01 Semarang.

Instrumen penelitian yang akan digunakan oleh peneliti adalah pedoman wawancara, pedoman observasi, serta pedoman dokumentasi untuk mengumpulkan data tentang pengembangan karakter siswa melalui ektrakurikuler karawitan di Sekolah Dasar Negeri Sendangguwo 01 Semarang.

Penelitian ini menggunakan pengumpulan data berupa observasi, wawancara dan dokumentasi.

\section{a) Observasi}

Nasution dalam (Sugiyono, 2017a) mengemukakan bahwa observasi merupakan dasar dari semua ilmu pengetahuan. Ilmuwan yang ada bekerja berdasarkan data, yaitu fakta mengenai dunia kenyataan yang dihasilkan dalam observasi.

Marshall dalam (Sugiyono, 2017a) menyatakan "through observation, the researcher learn about behavior and the meaning attached to those behavior". Dengan observasi, peneliti dapat belajar mengenai perilaku, serta makna dari perilaku.

Penelitian ini peneliti akan menggunakan observasi terstruktur. (Sugiyono, 2017b), "observasi terstruktur adalah observasi yang telah dirancang secara sistematis, tentang apa yang akan diamati, kapan dan dimana tempatnya, jadi observasi terstruktur dilakukan apabila peneliti telah tahu dengan pasti tentang variabel apa yang akan diamati."

Observasi akan dilakukan di Sekolah Dasar Negeri Sendangguwo 01 Semarang dengan objek siswa yang mengikuti kegiatan ekstrakurikuler karawitan. Observasi akan dilakukan dengan mengamati secara mendalam mengenai proses pembelajaran dari kegiatan ekstrakurikuler karawitan. 
Observasi pertama dilakukan pada hari senin tanggal 07 Oktober 2019, untuk mengetahui pelaksanaan kegiatan ekstrakurikuler karawitan di Sekolah Dasar Negeri Sendangguwo 01 Semarang dan untuk observasi kedua pada hari selasa tanggal 08 Oktober 2019, mengamati proses pembelajaran ekstrakurikuler karawitan di Sekolah Dasar Negeri Sendangguwo 01 Semarang.

\section{b) Wawancara}

(Sugiyono, 2017a) wawancara merupakan pertemuan antara dua orang yang bertukar informasi atau ide melalui sesi tanya jawab sehingga dapat diubah menjadi makna dalam suatu topik tertentu.

Wawancara yang digunakan peneliti adalah wawancara tidak tersetruktur atau terbuka, wawancara ini sering digunakan dalam penelitian tentang subyek yang diteliti. Wawancara tidak terstruktur adalah wawancara yang bebas di mana peneliti tidak menggunakan pedoman wawancara yang telah tersusun secara sistematis dan lengkap untuk pengumpulan datanya (Sugiyono, 2017a).

Wawancara dilakukan di Sekolah Dasar Negeri Sendangguwo 01 Semarang dengan objek kepala sekolah, pelatih karawitan dan siswa yang mengikuti kegiatan ekstrakurikuler karawitan.

Wawancara pertama dengan kepala sekolah yang dilakukan pada hari senin tanggal 07 Oktober 2019, untuk mengetahui (1) pelaksanaan ekstrakurikuler karawitan di Sekolah Dasar Negeri Sendangguwo 01 Semarang, (2) fungsi ekstrakurikuler karawitan bagi sekolah dan bagi siswadi Sekolah Dasar Negeri Sendangguwo 01 Semarang.

Wawancara kedua dengan pelatih karawitan yang dilakukan pada hari selasa tanggal 08 Oktober 2019, untuk mengetahui (1) pelaksanaan ekstrakurikuler karawitan di Sekolah Dasar Negeri Sendangguwo 01 Semarang, (2) proses pembelajaran ekstrakurikuler karawitan di Sekolah Dasar Negeri Sendangguwo 01 Semarang, (3) fungsi ekstrakurikuler karawitan bagi sekolah dan bagi siswa di Sekolah Dasar Negeri Sendangguwo 01 Semarang.

Informan dalam penelitian ada 3 yaitu sebagai berikut :

1) Kepala sekolah (Riyani, S.Pd. SD)

Wawancara dengan kepala sekolah bertujuan untuk memperoleh informasi tentang kegiatan ekstrakurikuler karawitan.

2) Pelatih Karawitan (Hadi Wiyono)

Wawancara dengan pelatih karawitan bertujuan untuk memperoleh informasi tentang proses pengembangan karakter melalui pembelajaran karawitan pada siswa.

3) Siswa (Danang dan Riana)

Wawancara yang dilakukan dengan beberapa siswa yang mengikuti kegiatan ekstrakurikuler karawitan bertujuan untuk mendapatkan informasi mengenai apa yang mereka dapatkan dari kegiatan ektrakurikuler karawitan.

\section{c) Dokumentasi}

(Sugiyono, 2017a) dokumen adalah catatan dari kejadian yang sudah lampau. Dokumen meliputi: gambar, tulisan, atau karya-karya monumental dari seseorang. Dokumentasi dalam penelitian ini meliputi foto dan video saat observasi, hasil wawancara dengan kepala sekolah, pelatih karawitan dan siswa yang mengikuti kegiatan ekstrakurikuler karawitan, dan hasil observasi siswa saat pembelajaran ekstrakurikuler karawitan di Sekolah Dasar Negeri Sendangguwo 01 Semarang.

\section{Hasil dan Pembahasan}

Untuk menjawab rumusan masalah mengenai bagaimana pelaksanaan ekstrakurikuler karawitan di Sekolah Dasar Negeri Sendangguwo 01 Semarang, peneliti melakukan wawancara dengan guru pelatih karawitan secara langsung. Pelaksanaan kegiatan ekstrakurikuler karawitan di Sekolah Dasar Negeri Sendangguwo 01 Semarang dilaksanakan di luar jam kegiatan belajar mengajar.

Kegiatan ekstrakurikuler karawitan di Sekolah Dasar Negeri Sendangguwo 01 Semarang dilakukan 1 minggu 1 kali pada hari selasa pukul 13.00 sampai 14.30. Pukul 13.30 di ikuti oleh kelas III dan IV, sedangkan pukul 14.45 dilakukan di ikuti oleh kelas V. Pelaksanaan ekstrakurikuler karawitan dilaksanakan selama 45 menit dan pelaksanaan ekstrakurikuler karawitan di dalam ruangan karawitan secara bergantian.

Berdasarkan hasil wawancara dengan kepala sekolah dan pelatih karawitan di Sekolah Dasar Negeri Sendangguwo 01 Semarang bahwa fungsi ekstrakurikuler karawitan bagi sekolah yaitu menanamkan cinta budaya sejak dini, meningkatkan mutu/kualitas pendidikan Sekolah Dasar Negeri 
Sendangguwo 01 Semarang, memberikan kesempatan pada siswa untuk memperluas pengalaman sosialnya, pembentukan karakter siswa dan siswa dapat bekerjasama dengan teman.

Berdasarkan hasil wawancara dengan kepala sekolah dan pelatih karawitan di Sekolah Dasar Negeri Sendangguwo 01 Semarang bahwa fungsi ekstrakurikuler karawitan bagi siswa yaitu pengembangan personal peserta didik melalui peluasan bakat dan minat, pengembangan potensi dan pemberian kesempatan untuk pembentukan karakter siswa, pengembangan kemampuan dan rasa tanggung jawab, memberikan kesempatan pada peserta didik untuk memperluas pengalaman sosial, dan mengembangkan kesiapan karir peserta didik melalui ekstrakurikuler karawitan.

Berdasarkan deskripsi data hasil penelitian yang telah terkumpul maka langkah selanjutnya yaitu pembahasan dari hasil penelitian tentang fungsi ekstrakurikuler karawitan di Sekolah Dasar Negeri Sendangguwo 01 Semarang dipaparkan sebagai berikut:

Ekstrakurikuler karawitan di Sekolah Dasar Negeri Sendangguwo 01 Semarang ini dilaksanakan setiap hari selasa. Peraturan Menteri Pendidikan dan Kebudayaan Republik Indonesia Nomor 62 Tahun 2014 menyebutkan bahwa kegiatan ekstrakurikuler adalah kegiatan kurikuler yang dilakukan oleh peserta didik di luar jam belajar kegiatan intrakurikuler dan kegiatan kokurikuler, di bawah bimbingan dan pengawasan satuan pendidikan.

Berdasarkan peraturan di atas, diketahui bahwa kegiatan ekstrakurikuler karawitan di Sekolah Dasar Negeri Sendangguwo 01 Semarang dilaksanakan di luar jam kegiatan belajar mengajar. Setiap kelas III, IV, dan V di jadwalkan untuk mengikuti kegiatan ekstrakurikuler karawitan dengan waktu 45 menit secara bergantian sesuai dengan jadwal yang sudah ditetapkan.

(Endraswara, n.d.) karawitan merupakan suatu keahlian, ketrampilan, kemampuan, atau seni memainkan, menggarap, atau mengolah suatu gendhing (lagu tradisional dalam seni karawitan Jawa yang dimainkan menggunakan alat musik gamelan) sehingga menjadi bagian-bagian kecil yang bersifat renik, rinci, dan halus.

Berdasarkan pengertian menurut (Endraswara, n.d.), dengan diadakan kegiatan ekstrakurikuler karawitan di Sekolah Dasar Negeri Sendangguwo 01 Semarang, peserta didik dapat memainkan atau mengelola suatu gendhing (lagu tradisional dalam seni karawitan Jawa yang dimainkan menggunakan alat musik gamelan).

Berdasarkan hasil pengumpulan data dari wawancara, dan observasi dapat diketahui bahwa fungsi ekstrakurikuler karawitan bagi sekolah yaitu menanamkan cinta budaya sejak dini dan dapat memajukan Sekolah Dasar Negeri Sendangguwo 01 Semarang atas prestasi karawitan. Sedangkan fungsi ekstrakurikuler karawitan bagi siswa yaitu pengembangan personal peserta didik melalui peluasan minat, pengembangan potensi dan pemberian kesempatan untuk pembentukan karakter siswa, pengembangan kemampuan dan rasa tanggung jawab memberikan kesempatan pada peserta didik untuk memperluas pengalaman sosial, dan mengembangkan kesiapan karir peserta didik melalui ekstrakurikuler karawitan. Sesuai dengan teori (Aqib, 2013) mengemukakan bahwa fungsi ekstrakurikuler sebagai berikut:

1. Pengembangan, yaitu fungsi kegiatan ekstrakurikuler untuk mengembangkan kemampuan dan kreativitas peserta didik sesuai dengan potensi, bakat dan minat mereka. Fungsi ekstrakurikuler di Sekolah Dasar Negeri Sendangguwo 01 Semarang sudah mengembangkan kemampuan dan keativitas peserta didik sesui dengan bakat dan minat peserta didik.

2. Sosial, yaitu fungsi kegiatan ekstrakurikuler untuk mengembangkan kemampuan dan rasa tanggung jawab sosial peserta didik. Fungsi ekstrakurikuler di Sekolah Dasar Negeri Sendangguwo 01 Semarang sudah mengembangkan kemampuan dan rasa tanggung jawab peserta didik.

3. Rekreatif, yaitu fungsi kegiatan ekstrakurikuler untuk mengembangkan suasana rileks, mengembirakan dan menyenangkan bagi peserta didik. Fungsi ekstrakurikuler di Sekolah Dasar Negeri Sendangguwo 01 Semarang sudah mengembirakan dan menyenangkan bagi peserta didik.

Dari penjabaran diatas mengenai fungsi ekstrakurikuler karawitan di Sekolah Dasar Negeri Sendangguwo 01 Semarang dapat disimpulkan bahwa fungsi ekstrakurikuler karawitan bagi sekolah untuk menanamkan cinta budaya sejak dini, meningkatan mutu/kualitas pendidikan. Sedangkan fungsi ekstrakurikuler karawitan bagi siswa untuk pengembangan potensi, minat dan bakat siswa, mengembangkan kesiapan karir siswa dan pembentukan karakter siswa. 


\section{Simpulan dan Saran}

Proses pembelajaran ekstrakurikuler karawitan di Sekolah Dasar Negeri Sendangguwo 01 Semarang menggunakan pola belajar karawitan sekolah dan latihan bareng. Pada pola pembelajaran karawitan tersebut pelatih karawitan membagi menjadi 3 kegiatan pembelajaran yaitu kegiatan pendahuluan, kegiatan inti dan kegiatan penutup.

Fungsi ekstrakurikuler karawitan bagi sekolah yaitu menanamkan cinta budaya sejak dini, meningkatkan mutu/kualitas pendidikan Sekolah Dasar Negeri Sendangguwo 01 Semarang, memberikan kesempatan pada siswa untuk memperluas pengalaman sosialnya, pembentukan karakter siswa dan siswa dapat bekerjasama dengan teman. Fungsi ekstrakurikuler karawitan basi siswa yaitu pengembangan personal peserta didik melalui peluasan bakat dan minat, pengembangan potensi dan pemberian kesempatan untuk pembentukan karakter siswa, pengembangan kemampuan dan rasa tanggung jawab, memberikan kesempatan pada peserta didik untuk memperluas pengalaman sosial, dan mengembangkan kesiapan karir peserta didik melalui ekstrakurikuler karawitan.

Berdasarkan simpulan yang dibuat peneliti terhadap pelaksanaan penelitian kualitatif mengenai fungsi ekstrakurikuler karawitan di Sekolah Dasar Negeri Sendangguwo 01 Semarang, peneliti memberikan saran sebagai berikut: 1) Sekolah hendaknya mempertahankan dan meningkatkan kegiatan ekstrakurikuler karawitan agar melalui kegiatan ekstrakurikuler karawitan menjadi wadah bagi siswa untuk pengembangan diri siswa dan mempelajari kebudayaan lokal sehingga dapat melestarikan kebudayaan lokal. 2) Sebaiknya pelatih tetap mengarahkan siswa yang tidak mengikuti kegiatan ekstrakurikuler karawitan untuk berada di dalam atau di luar ruangan karawitan walaupun hanya melihat teman-temannya bermain karawitan. Hal ini dilakukan agar siswa tersebut dapat mengenal karawitan. 3) Dalam kegiatan ekstrakurikuler karawitan merupakan kesempatan bagi siswa juga untuk mengembangkan potensi merekadalam bermain alat musik tradisional dan menyayikan gendhing gendhing jawa.

\section{Daftar Rujukan}

Aqib, Z. (2013). Model-Model, Media, dan Strategi Pembelajaran Kontekstual (Inovatif). Yrama Widya.

Arisyanto, P., Sundari, R. S., \& Untari, M. F. A. (2018). Pembelajaran Ekstrakurikuler Tari Untuk Penanaman Karakter Bagi Siswa SD Negeri Gayamsari 02 Semarang. Jurnal Pendidikan Dan Kajian Seni, 3(1), 1-13. https://doi.org/10.30870/jpks.v3i1.4062

Endraswara, S. (n.d.). Laras Manis Tuntunan Praktis Karawitan Jawa. Kuntul Press.

Fitri, A., Muda, I., \& Badaruddin. (2018). The Influence of Good Corporate Governance, Leverage, and Profitability on Earning Management with Firm Size as Moderating Variable in the Banking Companies Listed In Indonesia Stock Exchange in the Period of 2012-2016. International Journal of Research and Review, 5(9), 49-66. https://doi.org/10.4444/ijrr.1002/747

Hambali, M., \& Yulianti, E. (2018). Ekstrakurikuler Keagamaan Terhadap Pembentukan Karakter Religius Peserta Didik Di Kota Majapahit. Pedagogik, 5(2), 193-208.

Mulyasa. (2016). Pengembangan Implementasi Kurikulum 2013. PT Remaja Rosdakarya.

Sidik, Yogi Pratama. 2018. Strategi Pembelajaran Karawitan Dalam Kegiatan Ekstrakurikuler Di SMP Negeri 1 Bodeh Kecamatan Bodeh Kabupaten Pemalang. Jurnal Seni Musik, Vol. 8(2); (137-149).

Sugiyono. (2017a). Metode Penelitian Kuantitatif, Kualitatif, dan R\&D. Alfabeta.

Sugiyono. (2017b). Statistiak untuk Penelitian. Alfabeta.

Sukmadinata, N. S. (2016). Metode Penelitian Pendidikan. PT Remaja Rosdakarya.

Syakir, M., Tamsah, H., \& Sani, A. (2017). Analisis Kegiatan Pendidikan Ekstrakurikuler Untuk Pembentukan Karakter Disiplin Siswa Di SMA Negeri 1 Sinjai Borong. Jurnal Mirai Management, 2(2), 108-125.

Wiyani, N. A. (2013). Membumikan Pendidikan Karakter di SD. Ar-Ruzz Media. 